\title{
EVIDÊNCIAS DE IRREGULARIDADES EM OSCIPS: UMA ANÁLISE DOS EXAMES DE AUDITORIA REALIZADOS PELO TRIBUNAL DE CONTAS DA UNIÃO
}

\author{
EVIDENCE OF IRREGULARITIES IN OSCIPS: AN AUDIT EXAMINATION \\ ANALYSIS CONDUCTED BY THE COURT OF AUDITORS OF THE UNION
}

\author{
LORENA LUCENA FURTADO \\ Universidade Federal do Paraná. Endereço: Programa de Pós-Graduação \\ em Contabilidade | Av. Prefeito Lothário Meissner, 632 | 80210-170 | \\ Curitiba/PR |Brasil. \\ (1) http://orcid.org/0000-0002-7202-447X \\ lorenlucena@gmail.com
}

\section{JOSIANE GIACOMELLI}

Faculdade Cenec de Joinville. Endereço: Rua Farroupilhas, 1207| 89211320 | Joinville/SC | Brasil.

(1) http://orcid.org/0000-0002-3403-6648

giacomellijosiane@gmail.com

\section{VICENTE PACHECO}

Universidade Federal do Paraná. Endereço: Programa de Pós-Graduação em Contabilidade | Av. Prefeito Lothário Meissner, 632 | 80210-170 | Curitiba/PR |Brasil.

(D)http://orcid.org/0000-0002-6500-2264

vpacheco@ufpr.br

\section{RESUMO}

Esta pesquisa identifica irregularidades cometidas nos termos de parceria firmados com Organizações da Sociedade Civil de Interesse Público (Oscip) em exames de auditoria realizados pelo Tribunal de Contas da União (TCU), além de verificar as práticas de accountability nas atividades de auditoria do TCU. Para operacionalizar o estudo procedeu-se com exame documental, técnica adotada para análise dos acórdãos do TCU concernentes às auditorias executadas nas prestações de contas das parcerias governamentais com Oscips. A pesquisa identificou 77 acórdãos com irregularidades no período de 2005 a 2016, que favoreceram um total de 62 Oscips envolvidas em desvios. As irregularidades estão relacionadas ao desconhecimento das normas na elaboração de prestação de contas, falta de controle administrativo adequado na execução dos recursos e, também, situações de superfaturamento financeiro e desvio de finalidades do projeto. Adicionalmente, observou-se que o controle das normas e leis é a principal vertente de análise do TCU quanto aos aspectos da accountability, carecendo de melhores evidenciações sobre o desempenho destas organizações e transparência na execução dos projetos.

Palavras-chave: Oscip. Accountability. Recursos públicos. 


\begin{abstract}
This research identifies irregularities committed in the terms of partnerships celebrated with Civil Society Organizations of Public Interest (Oscip) in audits conducted by the Federal Court of Accounts (TCU), as well as to verify accountability practices in TCU audit activities. In order to operationalize the study, we adopted a document and technical examination to analyze TCU's judgments regarding the audits executed in the accounts of government partnerships with Oscips. The research identified 77 judgments with irregularities in the period from 2005 to 2016 , which favored a total of 62 Oscips involved in deviations. The irregularities are related to the lack of knowledge of the norms in the elaboration of accountability, lack of adequate administrative control in the execution of the resources, and also, situations of financial overbilling and deviation of project purposes. Additionally, we observed that the control of norms and laws is the main aspect of the TCU's analysis regarding aspects of accountability, lacking better pieces of evidence on the performance of these organizations and transparency in the execution of the projects.
\end{abstract}

Keywords: Oscip. Accountability. Public funds.

\title{
1 INTRODUÇÃO
}

O terceiro setor tem sua importância na medida em que fornece uma variedade de bens e serviços diferenciados, atende as necessidades de grupos específicos e proporciona maior compreensão das suas peculiaridades (Thompson \& Williams, 2014). Devido às características distintas dos seus produtos, tais entidades têm uma vantagem competitiva sobre os setores público e privado na entrega desses bens e serviços (Wainwright, 2002), o que pode reduzir pressões sobre o setor público em momentos de dificuldade financeira (Dart, 2004).

No Brasil, as Organizações da Sociedade Civil de Interesse Público (Oscip), pertencentes ao terceiro setor, foram instituídas pela Lei ${ }^{\circ}$ 9.790/99, com qualificação outorgada pelo Poder Público a pessoas jurídicas de direito privado, sem fins lucrativos, para desempenhar serviços sociais não exclusivos do Estado, com incentivos e fiscalização por parte do Poder Público, sendo o ordenamento jurídico estabelecido através de Termo de Parceria (Di Pietro, 2005). Uma das motivações para a existência destas organizações se deve à necessidade de ter organismos menos burocráticos para poder apoiar o Estado em suas atividades (Mânica, 2007).

Enquanto prestadores de serviços para a sociedade e detentores de recursos públicos, o foco recai sobre a responsabilidade que as Oscips têm de apresentar resultados; por isso, a prestação de contas tende a convergir aos preceitos da accountability (Cameron, 2004). O monitoramento e a avaliação são indicativos importantes para a consecução dos serviços prestados e para evidenciar a responsabilidade das organizações do terceiro setor (Shaw \& Allen, 2006).

No Brasil, o Tribunal de Contas da União (TCU) realiza o procedimento de auditoria em órgãos públicos contratantes de forma a garantir o emprego da accountability nos contratos firmados (Brasil, 2000).

O intuito das auditorias é analisar a legalidade e a legitimidade dos atos de gestão dos responsáveis no que diz respeito aos aspectos contábil, financeiro, orçamentário e patrimonial. As irregularidades encontradas por parte do TCU, como desfalque ou desvio de recursos, bens ou valores públicos, fraudes e ausência do dever de prestar contas, são relacionadas em relatórios de auditoria. A partir de condutas irregulares são enviadas propostas de encaminhamento e determinações denominadas acórdãos (Brasil, 2000).

Nos contratos firmados com entes públicos, em especial os termos de parceria pactuados entre Oscips e órgãos públicos, há desvio da responsabilidade em relação aos recursos destinados, um prejuízo social. Na literatura, as evidências apontam que o crescimento da 
quantidade de contratos entre os órgãos públicos e as organizações do terceiro setor vem acompanhado também de desvios de finalidade, que geram dúvidas sobre suas estruturas em termos técnicos e físicos (Guimarães, 2008).

Neste sentido, a fim de identificar a responsabilidade na prestação de contas sobre a aplicação de recursos públicos no interesse social, esta investigação dispõe da seguinte questão de pesquisa: quais irregularidades são praticadas pelas Oscips que utilizam recursos públicos, quando analisadas as auditorias realizadas pelo TCU? O objetivo geral é identificar as irregularidades praticadas pelas Oscips, mediante análise documental das auditorias realizadas pelo TCU. Assim, por meio dos acórdãos elaborados pelo Tribunal, pretende-se demonstrar as principais irregularidades evidenciadas nos recursos repassados para as Oscips nos termos de parceria firmados com o Estado.

Considerando que, para a gestão governamental as auditorias são entendidas como uma ação de controle por parte da Administração Pública com preceitos de execução pelo TCU, com o objetivo de promover e estabelecer a accountability sobre aqueles gestores de recursos públicos (Grateron,1999; Castaldelli Júnior, 2010), tem-se a importância de identificar as causas das irregularidades cometidas pelas Oscips. Assim, identificar quais são os mecanismos de auditoria praticados pelo TCU permite apontar comportamentos relacionados à questão de transparência e responsabilidade perante os seus beneficiários (Rodríguez, Pérez \& Godoy, 2012; Valencia, Queiruga \& Gonzáles-Benito, 2015).

Esta investigação contribui com a discussão sobre se há vantagem em determinadas áreas sociais terem suas atividades executadas apenas pelo Estado, ou se a disseminação da responsabilidade para entidades do terceiro setor é proveitosa para a sociedade e eficiente quanto ao investimento dos recursos públicos, além de abordar a responsabilidade das Oscips perante os seus diversos beneficiários, base para a evidenciação da accountability e a atuação do TCU enquanto órgão fiscalizador.

\section{REFERENCIAL TEÓRICO}

\subsection{Entidades do terceiro setor}

A expressão "terceiro setor" surgiu por meio de uma pesquisa realizada em quarenta países, em 1990, pela Johns Hopkins, chamada de "Comparative Nonprofit Sector Project", cujo termo em inglês, "sem finalidade de lucro", em seu sentido estrito significa apenas a não distribuição de seus lucros aos donos ou acionistas, mas que tem uma finalidade amplamente maior, devido ao papel que exerce na sociedade (Salamon, 1996). As organizações do terceiro setor têm o seu destaque em países como Austrália (Furneaux \& Ryan, 2014), Alemanha (Bode \& Brandsen, 2014), Itália (Ranci, 2015), Estados Unidos (Garrow, 2010) e Reino Unido (Clifford, Geyne-Rahme \& Mohan, 2013), na medida que são vistas como importantes organismos prestadores de serviços públicos. Sua origem na América Latina se dá por meio de iniciativas com ideologia de desenvolvimento em países com regimes totalitários, na década de 1950 (Landim, 1987).

De modo geral, as organizações sociais são essenciais para a consecução de serviços que não são exclusivos do Estado (Sano, 2003). Especificamente no Brasil, algumas entidades se concentram em exercer o papel comunitário e assistencialista que hoje é de responsabilidade do Estado, podendo, para tanto, utilizar recursos públicos ou privados recebidos e exercer o papel de gestoras de atividades que aproximam solidariedade e gestão administrativa (Martins, 2004).

Clifford et al. (2013) afirmam que o setor público continua a ser a maior fonte única de financiamento de tais entidades em países desenvolvidos. Com isso, as organizações do terceiro setor passam a ter exigências práticas na adoção dos requisitos já operacionalizados pelo setor público (Thompson \& Williams, 2014). Esse contato com a área pública fornece às entidades legitimidade e segurança para com as suas ações (Garrow, 2010). 
Não obstante, exigências por parte da sociedade como transparência (Campos, Moreira \& Scalzer, 2014; Valencia et al., 2015) e práticas de avaliações mais extensivas, por aqueles que financiam os projetos elaborados pelas entidades (Arvidson, 2009), nascem com a responsabilidade imputada às entidades do terceiro setor. $\mathrm{O}$ monitoramento defendido é aquele que tende a privilegiar a mensuração dos resultados no meio social e econômico, em detrimento da análise simples dos procedimentos interpostos na execução dos projetos realizados, ou seja, a simples conferência de documentação (Kendall \& Knapp, 2000; Shaw \& Allen, 2006). Além disso, há a defesa da obrigação de essas entidades realizarem prestação de contas (Abouassi \& Trent, 2016), sendo que qualquer irregularidade ou ilegalidade na utilização dos recursos ou bens públicos deve ser objeto de fiscalização por parte dos órgãos responsáveis (Paes, 2004).

\subsection{Accountability e o papel das auditorias}

Nas organizações criadas sem fins lucrativos, os valores ali aportados são provenientes de tributos e doações. Neste contexto, a presença de beneficiários, e não de clientes, se torna clara. Para esses beneficiários, há risco elevado no aporte de recursos em tais organizações, pois não é permitido retirar os valores investidos, assim como ocorre no mercado de capitais. Logo, tem-se a relação entre agente (gestor) e principal (beneficiário) (Sunder, 2014).

$\mathrm{O}$ agente tem a incumbência de executar a atividade que lhe foi atribuída e, para quitar tal responsabilidade, deverá prestar contas ao principal. No contexto da accountability, a prestação de contas decorre da obrigação da relação existente no contrato firmado entre os atores envolvidos (Nakagawa, 1993). Accountability refere-se à capacidade que uma organização tem de manter a confiança da sociedade por meio da divulgação de informações importantes para aqueles que a apoiam, sem se eximir de sua missão e de práticas de gestão adequadas (Valencia et al., 2015). Dentro da accountability, o agente tem a obrigação de explicar sua conduta e enfrentar as consequências do julgamento do principal (Bovens, 2006).

A prática da accountability no terceiro setor vai além de atender determinados grupos de stakeholders, cujo intuito do agente tem por finalidade a captação de recursos. Ela abrange questões mais extensivas a vários interessados e busca produzir relações complexas com toda a comunidade (Coule, 2015; Knutsen \& Brower, 2010; Ebrahim, 2009; Ebrahim, 2003a), já que a essência da accountability está baseada nas relações entre organizações e sociedade e/ou stakeholders (Gray, Bebbington \& Collison, 2006; Miller, 2002). Desta forma, há a necessidade de construção do senso de responsabilidade por parte dos gestores das entidades do terceiro setor, fornecendo informações que atendam expectativas legítimas quanto às necessidades de todos os envolvidos. (Sinclair, 1995; Larry, 1995; Fry, 1995; Chisolm, 1995).

No estudo de Rocha (2009), a accountability é identificada como um processo similar à "prestação de contas" realizada pelas ações do TCU. Por seu turno, a pretensão da fiscalização é investigar a gestão das organizações, a fim de resguardar os recursos financeiros direcionados a projetos que visam ao interesse social (Kluvers, 2003; Koppell, 2005). Saxton (2012) e Benjamin (2008) identificaram em seus estudos sobre o papel da acountability nas prestações de contas das instituições do terceiro setor e concluíram que a divulgação das informações estava mais concentrada em fornecer análises financeiras e de desempenho do que efetivamente estabelecer mecanismos de diálogo, com a participação dos interessados na busca do engajamento interativo.

Existem estudos que mapeiam quais características podem ser analisadas para se chegar a um meio de se evidenciar a accountability. Características essas que servem como base de construção ao que buscar na realização de auditorias. Entre elas estão aquelas destacadas por Denhardt e Denhardt (2000), que indicam a prestação de contas com base nos controles burocrático, de performance e democrático. O primeiro tem por intuito a análise da conformidade das leis e normas. O segundo visa ao controle do desempenho. E o terceiro, além do desempenho dos recursos públicos investidos, tem como foco analisar o comportamento dos gestores perante tais recursos e a sociedade. 
Koppel (2005) enfatiza que a accountability pode ser identificada quando a entidade tem transparência nas prestações de contas, a fim de atender aos interesses da sociedade e não os seus particulares; quando existe a sujeição de responder pelos seus atos, mesmo que estes venham a resultar em punições; quando há controle interno relativo às suas atividades finalísticas; quando a entidade tem responsabilidade relativa às normas que deve seguir; e, quando há responsividade no que diz respeito a responder ao que é demandado pela sociedade.

Os exames através da auditoria na prestação de contas das entidades do terceiro setor desempenham o papel de controle dos contratos e da adequada utilização de recursos recebidos. A auditoria contábil, em especial, identifica as normas e diretrizes relacionadas às demonstrações contábeis, bem como aos dispositivos legais que objetivam a condução das finalidades operacionais e de negócio do terceiro setor (Graciliano, Filho, Nunes \& Zampa, 2010). As informações contábeis, sob a ótica da responsabilidade, são importantes para os seus diversos stakeholders, uma vez que dispõem de dados que evidenciam a utilização dos recursos, públicos ou privados, nos projetos desenvolvidos por tais entidades (Campos et al., 2014).

Na pesquisa de Do Carmo Dalto, Lopez e Martinez (2014), houve a identificação da tipologia de irregularidades que ocorreram nos contratos administrativos entre as universidades federais e fundações de apoio no Brasil no período de 2006 a 2010, sendo as mais constantes aquelas referentes ao desvio de finalidade, decorrentes principalmente das falhas dos controles internos das universidades federais no controle finalístico dos recursos junto às fundações de apoio. Os autores salientam que boas práticas, como transparência, avaliação e mecanismos de ouvidoria, precisam ser incentivadas a fim de tornar factível a responsabilidade dos gestores.

Além das fundações de apoio, as Oscips são objeto de estudo sobre a gestão dos recursos atribuídos através de termos de parceria, visto o seu comportamento extensor das atividades da administração pública (Sano, 2003). Assim, focar na investigação e eficiência dos termos de parceria realizada com Oscips é uma das formas de identificar a responsabilidade daqueles que coordenam recursos públicos. A falta de responsabilização na prestação de contas, segundo os pressupostos da accountability, contribui para o desvio de finalidade e pode provocar o aumento do número de irregularidades dos recursos estatais em organizações do terceiro setor (Guimarães, 2008).

Considerando as obrigações, Soldi et al. (2007) alertam que divulgar qualquer tipo de informação não resolve o problema da falta de transparência, uma vez que a informação disseminada deve conter qualidade. Logo, há a necessidade de mudança no comportamento das organizações em divulgar informações com acurácia, principalmente em relação à prática de monitoramento e avaliação (Kendall \& Knapp, 2000; Ebrahim, 2003b). Assim, salienta-se a necessidade de pesquisas sobre accountability e sobre a legislação que rege o tema com foco no contrato de gestão, instrumento que cria o vínculo entre o Estado e as entidades, e que define as atribuições, responsabilidades e obrigações de cada uma das partes.

\section{METODOLOGIA}

O procedimento metodológico se deu por estudo exploratório com levantamento e exame de documentos, sistemática que serviu para compilar as informações disponíveis acerca dos relatórios de auditorias, prestação e tomada de contas realizadas nos órgãos públicos que firmaram Termo de Parceria com Oscips. Após o levantamento dos documentos, para fins de apuração detalhada das informações, realizou-se o exame dos dados disponíveis nos documentos, para identificar as irregularidades cometidas pelas Oscips e a accountability realizada pelo TCU nas auditorias. O documento disponível para o exame é denominado acórdão, sendo este a manifestação por parte do TCU das decisões sobre determinado caso derivado das auditorias, prestações e tomada de contas.

A pesquisa realizada consiste nas seguintes atividades:

a) levantamento dos acórdãos no sítio eletrônico no TCU; 
b) identificação dos acórdãos que apresentaram as palavras "irregularidade" e Oscip;

c) tratamento da amostra inicial e exclusão daqueles acórdãos que não apresentavam de fato irregularidade entre Oscips;

d) identificação (principalmente das instituições contratadas e contratantes), localidade, tipo, ano e natureza da irregularidade de acordo com a Lei ${ }^{\circ}$ 9.790/99 e natureza da atividade executada pela Oscip e;

e) exame dos dados presentes nos acórdãos.

Segundo Godoy (1995), o exame de documento apresenta importante vantagem para a pesquisa, uma vez que os documentos analisados não sofrem alterações ao longo do tempo, e dessa forma se mantêm entrelaçados àquele contexto histórico. Como definição de pesquisa documental, Godoy (p. 22, 1995) aborda que é "o exame de materiais, de natureza diversa, que ainda não receberam um tratamento analítico, ou que podem ser reexaminados, buscando-se novas e/ ou interpretações complementares (...)".

A primeira parte da pesquisa consistiu em realizar o levantamento de aspectos referentes às características das Oscips e das irregularidades, conforme segue:

a) observação do ano da emissão do acórdão relativo aos achados de auditoria, prestação ou tomada de contas, utilizado como marco da infração;

b) observação da aglomeração por estado federativo do Brasil da contratante para indicar as regiões mais afetadas por irregularidades;

c) observação dos tipos de irregularidades apontadas pelo TCU e;

d) mensuração da repetição das irregularidades apontadas nos acórdãos para posterior análise dos resultados encontrados, tal como no trabalho de Do Carmo Dalto et al. (2014).

Após observar as características específicas das Oscips e dos tipos de irregularidades, a segunda parte objetivou realizar o exame dos dados constantes nos acórdãos, apresentando codificações como segue:

a) primeira codificação indicando os tipos de irregularidades apontadas nos acórdãos e;

b) segunda codificação agrupando tipos de irregularidades em modalidades com base na Lei $n^{\circ}$ 9.790/99.

Por último, foram apresentadas informações suplementares referentes às justificativas dadas pelas Oscips e as opiniões emitidas pelo TCU, além da classificação da accountability. Para esse fim, esta investigação teve como base o trabalho de Denhardt e Denhardt (2000) e Koppel (2005). O primeiro classifica o tipo de prestação de contas em: burocrático, de performance e democrático. Já o segundo trabalho caracteriza a accountability no que diz respeito a transparência, sujeição, controle, responsabilidade e responsividade. $O$ estudo compreendeu os anos de 2005 a 2016, período em que, no site do TCU, as observações estão concentradas.

\section{EXAME DOCUMENTAL (ACÓRDÃOS)}

Analisados os acórdãos de relatórios de auditoria, prestação e tomada de contas no portal do TCU, de 265 relatórios retirados do site, 77 apresentavam constatações de irregularidade no período de 2005 a 2016, assim distribuídos: 2005 - um acórdão; 2007 - três acórdãos; 2008 dois acórdãos; 2009 - três acórdãos; 2011 - oito acórdãos; 2012 - seis acórdãos,; 2013 - três acórdãos; 2014 - oito acórdãos; 2015 - vinte e quatro acórdãos; e 2016 - dezenove acórdãos. Para melhor visualizar a amostra, segue a seleção na Tabela 1: 
Tabela 1

\section{Seleção da Amostra}

\begin{tabular}{l|l}
\hline Total de acórdãos, prestações e tomadas de contas no período de 2005 a 2016 & 265 \\
\hline Acórdãos retirados por conter apenas os termos “irregularidade", ou "irregularidade" e "fundação de apoio & 188
\end{tabular} a universidades", ou "irregularidade" e "convênio"

\begin{tabular}{lll}
\hline Acórdãos que continham os termos "irregularidades" e "Oscip" & $\mathbf{7 7}$ \\
\hline
\end{tabular}

Fonte: Dados da pesquisa (2017).

Os resultados dos acórdãos da amostra apresentaram 62 Oscips diferentes, dentro de um total de 77 acórdãos analisados. A amostra em si pode ser caracterizada como um censo no qual se buscou identificar as características presentes nos acórdãos com as nomenclaturas "irregularidades" e "Oscip". Dessa forma, trata-se de uma amostragem intencional, não probabilística, e os achados deste trabalho estão relacionados apenas aos 77 acórdãos aqui analisados. O número de Oscips contempladas se deve ao fato de que houve entidades que geraram irregularidades com recursos públicos em mais de um Termo de Parceria, o que demonstra que as parcerias são assinadas independentemente da existência de contratos anteriores com irregularidades. Nas constatações do TCU observa-se que há certo período de tempo para a elaboração do acórdão, diferente da data de assinatura do Termo de Parceria. Sendo que este pode ser levado como fator de assinatura de contratos com entidades que posteriormente foram indicadas com irregularidades. A Tabela 2 aponta as Oscips analisadas por finalidade.

Tabela 2

Oscips por finalidade, relativo aos Termos de Parceria com Irregularidades no TCU de
\begin{tabular}{lcc}
$\mathbf{2 0 0 5}$ a 2016 & Frequência & $\%$ \\
\hline Finalidade & 16 & $25,8 \%$ \\
\hline Assistencial & 15 & $24,2 \%$ \\
\hline Finalidade não cadastrada & 6 & $9,7 \%$ \\
\hline Educacional & 6 & $9,7 \%$ \\
\hline Pesquisas & 5 & $8,1 \%$ \\
\hline Cidadania & 5 & $8,1 \%$ \\
\hline Cultural & 4 & $6,5 \%$ \\
\hline Creditícia & 2 & $3,2 \%$ \\
\hline Ambiental & 1 & $1,6 \%$ \\
\hline Jurídica & 1 & $1,6 \%$ \\
\hline Saúde & 1 & $1,6 \%$ \\
\hline Voluntariado & $\mathbf{6 2}$ & $\mathbf{1 0 0 , 0 \%}$ \\
\hline Total Geral & &
\end{tabular}

Fonte: Dados da pesquisa (2017).

Dentre as entidades pertencentes à amostra estudada, prevalecem a finalidade assistencial, com 26,2\% dos casos, e as finalidades não cadastradas, com 24,6\%. As entidades dentro deste item atuam em mais de uma finalidade e não podem ser classificadas em uma única atividade preponderante. Atualmente existem 7.636 entidades cadastradas junto ao Ministério da Justiça e Segurança Pública, e apenas 3.608 possuem em seu cadastro a sua finalidade. Destas, $1.338(37,08 \%)$ são pertinentes à finalidade assistencial, seguidas de $553(15,33 \%)$ com a finalidade ambiental e 347 (9,62\%) com a finalidade cultural.

A análise relativa ao estado e à região do Brasil de origem das Oscips pesquisadas indica que a região Nordeste possui o maior número de entidades com irregularidades no TCU, com 21 Oscips, seguida pela região Sudeste, com 16. A Tabela 3 apresenta dados de irregularidades constatadas, dos estados com 10 ou mais tipos de irregularidades, e ainda os tipos de irregularidade com cinco incidências ou mais. O resultado da tabela denota que $45,5 \%$ das irregularidades estavam concentradas em apenas seis estados. 
Tabela 3

Tipo de irregularidade cometida pelas Oscips identificadas pelo TCU por unidade federativa - 2005 a 2016

\begin{tabular}{|c|c|c|c|c|c|c|c|}
\hline $\begin{array}{c}\text { Tipo de } \\
\text { irregularidade }\end{array}$ & Bahia & $\begin{array}{l}\text { Distrito } \\
\text { Federal }\end{array}$ & Pernambuco & Paraná & $\begin{array}{c}\text { Rio de } \\
\text { Janeiro }\end{array}$ & $\begin{array}{c}\text { São } \\
\text { Paulo }\end{array}$ & $\begin{array}{c}\text { Frequênci } \\
\mathbf{a}\end{array}$ \\
\hline $\begin{array}{lr}\text { Apresentação } & \text { da } \\
\text { prestação de } & \text { contas } \\
\text { incompleta } & \text { e } \\
\text { insubsistente }\end{array}$ & 2 & 2 & 2 & 3 & 2 & 2 & 13 \\
\hline $\begin{array}{l}\text { Descumprimento de } \\
\text { obrigação de prestar } \\
\text { contas à concedente }\end{array}$ & 2 & 0 & 0 & 0 & 1 & 2 & 5 \\
\hline $\begin{array}{ll}\text { Ausência } & \text { de } \\
\text { comprovação } & \text { de } \\
\text { despesas } & \end{array}$ & 1 & 2 & 4 & 8 & 3 & 2 & 20 \\
\hline $\begin{array}{l}\text { Movimentação } \\
\text { irregular em contas } \\
\text { bancárias }\end{array}$ & 0 & 1 & 1 & 3 & 1 & 2 & 8 \\
\hline $\begin{array}{l}\text { Superfaturamento } \\
\text { de faturas }\end{array}$ & 1 & 2 & 2 & 5 & 1 & 0 & 11 \\
\hline $\begin{array}{l}\text { Emissão de notas } \\
\text { fiscais/faturas em } \\
\text { desconformidade } \\
\text { com as respectivas } \\
\text { planilhas de custos }\end{array}$ & 0 & 1 & 2 & 4 & 1 & 0 & 8 \\
\hline $\begin{array}{l}\text { Não elaboração do } \\
\text { objeto principal do } \\
\text { termo de parceria }\end{array}$ & 1 & 0 & 0 & 2 & 0 & 2 & 5 \\
\hline $\begin{array}{l}\text { Pagamento de } \\
\text { despesas sem nexo } \\
\text { com o objetivo do } \\
\text { termo de parceria }\end{array}$ & 1 & 1 & 1 & 2 & 1 & 3 & 9 \\
\hline $\begin{array}{lr}\text { Alocação } & \text { de } \\
\text { funcionário } & \text { da } \\
\text { Oscip como gestor } \\
\text { do } \quad \text { contrato, } \\
\text { infringindo o art. } 3^{\circ} \\
\text { da Lei n' 9.790/99. }\end{array}$ & 0 & 0 & 0 & 2 & 1 & 2 & 5 \\
\hline $\begin{array}{ll}\text { Ausência } & \text { de } \\
\text { comprovação } & \text { do } \\
\text { serviço prestado } & \\
\end{array}$ & 1 & 1 & 2 & 2 & 1 & 1 & 8 \\
\hline Frequência & 9 & 10 & 14 & 31 & 12 & 16 & 92 \\
\hline$\%$ & $4,5 \%$ & $5,0 \%$ & $6,9 \%$ & $15,3 \%$ & $5,9 \%$ & $7,9 \%$ & $45,5 \%$ \\
\hline
\end{tabular}

Fonte: Dados da pesquisa (2017).

As Oscips que apresentaram os maiores números de irregularidades pertencem aos estados da Bahia (9), Distrito Federal (10), Pernambuco (14), Paraná (31), Rio de Janeiro (12) e São Paulo (16). O estado do Paraná abrangia 7 entidades (11,3\% do total) dentro da pesquisa, mas na elaboração da análise por tipo de irregularidade, é o estado que mais apresenta situações irregulares promovidas pelas Oscips analisadas, com 15,3\% dos casos. O estado de Pernambuco continha o maior número de entidades encontradas, $14,5 \%$ (9 casos) e dispunha de $6,9 \%$ do total de irregularidades verificadas. As irregularidades encontradas tiveram origem nos estados em que as Oscips foram contratadas, sendo que a origem da entidade contratada pode ser diferente do local onde o serviço foi prestado.

Pelos registros expressados pelo TCU, existem irregularidades cometidas por falta de conhecimento, por parte dos dirigentes, da forma adequada de se fazer a prestação de contas. Houve situações com fortes indícios de criação de entidades de "fachada", criadas 
exclusivamente com a finalidade de desvio de recursos públicos. Outros casos apresentaram situações em que os dirigentes das Oscips receberam valores por meio dos termos de parceria, o que é vedado pela Lei $n^{\circ}$ 9.790/99. Tais evidências demonstram falta de controle por parte da contratante, além de falta de responsabilidade tanto da contratante quanto da contratada (Koppel, 2005).

Os dados foram coletados e analisados considerando o tipo de irregularidade encontrada nos acórdãos. Durante a coleta observou-se acórdãos que estavam relacionados devido a recursos requeridos pelas entidades em análise. Portanto, foram excluídos acórdãos que tratavam dos mesmos Termos de Parceria, Oscips e entes públicos, totalizando 77 acórdãos como amostra final do estudo. Na Tabela 4 são apresentadas as tipologias encontradas e classificadas por quantidade de entidades em que ocorreram tais irregularidades.

Tabela 4

Quantidade de entidades por tipologia das irregularidades - 2005 a 2016

\begin{tabular}{|c|c|c|}
\hline Modalidade & Tipo de irregularidade & Frequência \\
\hline \multirow{5}{*}{$\begin{array}{l}\text { Comprovação de } \\
\text { documentos }\end{array}$} & Ausência de comprovação das despesas executadas & 26 \\
\hline & Elaboração de orçamento não confiável & 5 \\
\hline & Inconsistência na comprovação da contrapartida do serviço & 4 \\
\hline & Falta de comprovação de recolhimento de tributos & 3 \\
\hline & Cheques depositados relativos a bancos não credenciados & 1 \\
\hline \multicolumn{2}{|r|}{ Total por modalidade } & 39 \\
\hline \multirow{2}{*}{ Prestação de contas } & Apresentação da prestação de contas incompleta e insubsistente & 17 \\
\hline & Descumprimento de obrigação de prestar contas à concedente & 15 \\
\hline \multicolumn{2}{|r|}{ Total por modalidade } & 32 \\
\hline \multirow{6}{*}{$\begin{array}{l}\text { Execução do objeto } \\
\text { físico }\end{array}$} & Ausência de comprovação do serviço prestado & 15 \\
\hline & $\begin{array}{l}\text { Emissão de notas fiscais/faturas em desconformidade com as } \\
\text { respectivas planilhas de custos }\end{array}$ & 10 \\
\hline & Não elaboração do objeto principal do Termo de Parceria & 7 \\
\hline & Alcance parcial dos objetivos do Termo de Parceria & 5 \\
\hline & Deficiência na fiscalização dos serviços & 3 \\
\hline & Abandono do Projeto & 1 \\
\hline \multicolumn{2}{|r|}{ Total por modalidade } & 41 \\
\hline \multirow{11}{*}{$\begin{array}{l}\text { Aplicação dos } \\
\text { recursos financeiros } \\
\text { do projeto }\end{array}$} & Superfaturamento de faturas & 16 \\
\hline & $\begin{array}{l}\text { Pagamento de despesas incompatível com o objetivo do Termo } \\
\text { de Parceria }\end{array}$ & 11 \\
\hline & Movimentação irregular em contas bancárias & 9 \\
\hline & $\begin{array}{l}\text { Depósitos em conta corrente para beneficiários sem vínculo } \\
\text { com o recurso }\end{array}$ & 4 \\
\hline & $\begin{array}{l}\text { Não identificação da destinação dos recursos sacados e do } \\
\text { respectivo credor }\end{array}$ & 4 \\
\hline & Aplicação de recursos dos termos de parceria sem necessidade & 4 \\
\hline & Presença de conflito de interesse & 3 \\
\hline & Sobras de Termo de Parceria não devolvidas aos cofres públicos & 3 \\
\hline & Falta de aplicação financeira para os recursos excedentes & 3 \\
\hline & Utilização indevida dos recursos de taxas administrativas & 3 \\
\hline & Pagamento de despesas em duplicidade & 1 \\
\hline \multicolumn{2}{|r|}{ Total por modalidade } & 61 \\
\hline $\begin{array}{l}\text { Aplicação nos } \\
\text { recursos humanos } \\
\text { do projeto }\end{array}$ & $\begin{array}{l}\text { Alocação de funcionário da Oscip como gestor do contrato } \\
\text { Burla dos direitos trabalhistas }\end{array}$ & 7 \\
\hline
\end{tabular}




\begin{tabular}{l|c|c}
\multicolumn{1}{c|}{} & Justificativa insuficiente para contratação de pessoal & 4 \\
\hline \multicolumn{2}{c}{ Total por modalidade } & 18 \\
\hline \multirow{2}{*}{$\begin{array}{l}\text { Inconsistência como } \\
\text { Oscip }\end{array}$} & Irregularidades na constituição da Oscip & 4 \\
\cline { 2 - 3 } & Serviços elaborados não constantes das finalidades da Oscip & 7 \\
\hline \multicolumn{2}{c}{ Total por modalidade } & 11 \\
\hline
\end{tabular}

Fonte: Dados da pesquisa (2017).

Os dados apresentados na Tabela 3 demonstram que a tipologia mais encontrada nos acórdãos analisados é Ausência de Comprovação de Despesas, com 26 casos, seguido de Apresentação de Prestação de Contas Incompleta e Insubsistente com 17 casos e Superfaturamento de Faturas, com 16 incidências. Os acórdãos têm como base para as constatações expressas na Tabela 3 a Lei n 9.790/99, que qualifica as Oscips. Sobre os recursos envolvidos, a ênfase dada nos acórdãos está na questão de a contratada não ter o controle adequado sobre os gastos incorridos com as despesas dos projetos. Os relatores do TCU, quando da análise dos termos de parceria, colocam como pressuposto para a execução do projeto que a Oscip contratada deve ter condições regulares para execução do objeto, incluindo recursos humanos e físicos. Na ausência desta estrutura, as falhas incorridas são vistas como faltas administrativas das contratadas.

Observa-se a ausência da prática da responsabilidade, apontada por Sinclair (1995), Fry (1995) e Chisolm (1995), para poder fornecer aos stakeholders informações condizentes com o objetivo fim da organização. A abordagem mais relacionada aos aspectos financeiros, com ausência de observações relacionadas ao desempenho, pode estar enfraquecendo as atitudes responsáveis dos gestores.

Diante da perspectiva apresentada por Guimarães (2008) ao afirmar que a investigação dos recursos públicos destinados às Oscips contribui para identificar a responsabilidade daqueles que coordenam recursos públicos, pode ser destacada a tipologia da irregularidade classificada como Conflito de Interesse. Nesse item foram encontrados serviços prestados por empresa privada subcontratada pela Oscip em que o sócio da empresa possuía parentesco em primeiro grau com o dirigente da Oscip que o contratou, demonstrando que há efetivamente interesses difusos à boa utilização dos recursos públicos e que, sem uma investigação ou auditoria, situações como esta não seriam constatadas. Graciliano et al. (2010), também afirmam que a auditoria é realizada para verificar se os dispositivos legais são efetivamente cumpridos, ponderando então que situações de conflito de interesse podem ser caracterizadas como distribuição indireta de lucros, o que está proibido pela Lei $n^{\circ}$ 9.790/99.

Sobre a tipologia de Irregularidade nas Prestações de Contas, aquelas atribuídas pelas decisões recaem não apenas sobre o responsável pela Oscip, mas também sobre aquele designado pela contratante como responsável pelo controle (indicação de servidor público ou constituição de comissão). Conforme destaca Bovens (2006), há uma obrigação clara de que o agente que utiliza recursos deve explicar a sua conduta; esta obrigação também é ampliada para aquele que realiza a contratação. Para tanto, há de ser identificada falha em relação à fiscalização por parte dos órgãos contratantes quanto ao acompanhamento e controle da prestação de serviço pela Oscip. Apesar de o foco desta investigação não estar direcionado à contratante, nos relatos dos acórdãos há um destaque quanto à recomendação da Lei ${ }^{\circ}$ 8.666/93 (Lei das Licitações) para que seja atribuída também para a realização de compras feitas pelas Oscips.

Analisando as modalidades, a percepção sobre os recursos financeiros tem destaque. Destaca-se o foco nas questões financeiras quando da realização da prestação de contas junto ao TCU. Isso vai de encontro ao colocado por Saxton (2012), porém não condiz com as questões referentes à análise do desempenho e finalidade de tais organizações, assim como o monitoramento de suas práticas e sua avaliação (Kendall \& Knapp, 2000; Ebrahim, 2003b). 
Cabe salientar que os dados financeiros, principalmente aqueles contábeis, são importantes para a identificação do uso de recursos públicos e privados por parte dos stakeholders (Graciliano, Filho, Nunes \& Zampa, 2010; Campos et al., 2014), o que não desqualifica o emprego destes na prestação de contas.

Nas discussões dos acórdãos desta pesquisa, os achados indicam que a accountability empregada pelo TCU foca no emprego dos recursos públicos por parte dos gestores designados para sua execução. Logo, há uma confirmação condizente com o estudo de Rocha (2009) quanto à prestação de contas como objeto importante no emprego da accountability. Também no exame documental foi possível observar que o foco está em um controle burocrático conforme destacado por Denhardt e Denhardt (2000), uma vez que a base para a investigação está direcionada à Lei no 9.790/99.

Concentrar na modalidade de aplicação nos recursos humanos do projeto realça os achados quanto a algumas características típicas da contratação de pessoal. Entre elas, designar pessoal da Oscip contratante, como gestor de um contrato, quando este desempenha atividades também na instituição contratada. Houve relatos acerca das obrigações trabalhistas e relacionadas à contratação de mão de obra a fim de facilitar os termos burocráticos, uma vez que por meio de órgãos públicos tal terceirização não seria possível devido à obrigação de concurso público. Esta situação é um indício de burla das regras para a utilização das Oscips para um interesse específico, utilizando-as para outros fins.

Com as características apresentadas, os objetos de controle interno das organizações que realizam o contrato devem ser mais bem observados para que se analise e identifique falhas que podem prejudicar a contratação de entidades que disponham de características qualificáveis para executar as atividades que não são exclusivas do Estado. Esta falha de controle interno é um destaque colocado por Koppel (2005), e uma das principais falhas detectadas na pesquisa de Do Carmo Dalto, Lopez e Martinez (2014) em universidades e fundações de apoio.

Destaque para a área da saúde, que, apesar de não ter representação na amostra desse estudo de forma significativa, passou por diversas recomendações do TCU por usar recursos do Sistema Único de Saúde (SUS) com a terceirização frequente dos serviços de saúde por meio das Oscips, sendo que o entendimento é que estas devem responder pela administração gerencial e não pela gerência propriamente dita de uma atividade pertinente ao Estado. Há entendimento por parte dos órgãos de fiscalização, como o TCU e o Tribunal de Contas do Estado (TCE), de que há desvio de finalidade por parte das entidades públicas ao contratar Oscips e outras entidades sem fins lucrativos. Esta é uma questão já destacada nos achados de Do Carmo et al.(2014).

Tendo como ponto de partida as Oscips, há também a constatação de desvio de finalidade em alguns Termos de Parceria firmados e inconsistência na entrega dos objetos contratados, ou ainda a não entrega do objeto contratado no Termo de Parceria. Esta irregularidade, o desvio de finalidade entre a Oscip e a contratada, se dá quando, além da prestação de contas dos valores financeiros, o objeto do contrato não é devidamente apresentado, fato evidenciado nas análises das auditorias do TCU, conforme a Tabela 4. A importância dada a estes itens ressalta a falta de estrutura administrativa, o que inclui instrumentos de controle. Tal evidência vai de encontro a uma das questões colocadas por Koppel (2005), que destaca que o controle é uma das formas de identificar a accountability na execução das atividades de uma entidade.

Deve-se observar que tais informações da prestação contas dos termos de parceria são repassadas aos órgãos públicos contratantes por uma obrigação legal. Porém, não há a obrigação de que esta prestação de contas deve ser tornada pública, favorecendo a transparência conforme destacado nas pesquisas de Campos et al. (2014) e Valencia et al. (2015). Com isso, além de prejuízos no quesito transparência, também podem ser observadas falhas na questão da responsividade, uma vez que a entidade não terá maiores preocupações além daquelas que são relacionadas a cobranças legais a respeito de informações.

Outro ponto importante é que nos acórdãos não foram observadas atuações das Oscips relacionadas a ter um diálogo constante com os diversos stakeholders. Esse é um item importante 
enfatizado por Gray, Bebbington \& Collison (2006) e Miller (2002), para fins de apresentar responsabilidade perante as partes interessadas. Essa ausência de observações quanto ao diálogo reflete também no prejuízo observado quanto à falta de transparência das organizações.

De forma geral, os achados nos acórdãos contribuem com a falta de controle por parte dos órgãos contratantes e das Oscips, e zelo na prestação de contas, o que indica que os mecanismos de controle são dotados de falhas, e até mesmo, em certos pontos, podem estar ausentes. Isto pode ser evidenciado, uma vez que há infrações recorrentes e até repetidas pela mesma Oscip em órgãos públicos diferentes. Os relatórios não apontam a realização de auditoria sobre esses Termos de Parceria por nenhuma das partes. Indica apenas que deve haver a prestação de contas, sendo este o objeto utilizado de verificações por parte do TCU das irregularidades apontadas nesta investigação.

\section{CONCLUSÃO}

O presente trabalho investigou as irregularidades praticadas pelas Oscips, mediante análise documental das auditorias realizadas pelo TCU. Tal objetivo teve como pretensão focar na questão da responsabilidade, tal como evidenciar questões relacionadas à accountability. Para operacionalizar a pesquisa foram coletados os acórdãos no sítio eletrônico do TCU, com posterior exame documental, perfazendo o período de 2005 a 2016.

Sobre as Oscips, os achados indicam irregularidades relacionadas a conflitos de interesse, tal como apontado por Graciliano et al. (2010), uma vez que haviam funcionários pertencentes ao quadro de pessoal de algumas Oscips que estavam presentes, também, no quadro de pessoal da contratada, realizando o papel de gestor do contrato firmado entre ambas. Outras irregularidades dizem respeito aos desvios de finalidade. Essa constatação vai de encontro ao apontado por Do Carmo et al. (2014), uma vez que o recurso veio a ser utilizado de forma indevida, como o caso de notas fiscais superfaturadas, e em alguns contratos o objeto não foi entregue como acordado.

Destaca-se também a falta de disciplinas de controle nas organizações e de responsabilidade quando da análise das peças das prestações de contas das entidades junto aos seus órgãos contratantes. Dos itens destacados por Koppel (2005), deve-se observar, em primeiro lugar, a questão da transparência, uma vez que se apresenta apenas o que é indicado como obrigatório pelo TCU, desconsiderando outras informações que a sociedade necessita para julgar a boa conduta das Oscips. Em segundo lugar, o controle deve ser analisado, visto que existem falhas relativas à gestão administrativa. Quanto à responsabilidade, apesar das normas existentes, ainda há falhas na prestação de contas, o que impacta neste item. Por último, a responsividade é um item que pode ser objeto de estudos futuros para se observar quais informações extras estão sendo divulgadas e como elas podem contribuir para o atendimento às necessidades da sociedade, relacionadas à atividade finalística da Oscip.

Ademais, a disciplina, por utilizar a licitação como meio de contratação, também se tornou recorrente nos achados do TCU, uma vez que tal prática não foi confirmada em nenhum dos relatórios analisados, bem como em medições de desempenho e transparência dos recursos empregados pelas Oscips por meio dos Termos de Parceria. Prática esta defendida nas pesquisas internacionais quando destacam uma maior avaliação dos projetos das organizações do terceiro setor (Arvidson, 2009), com práticas de medir os resultados em detrimento da análise simplista dos processos realizados (Shaw \& Allen, 2006).

Em relação ao exame dos acórdãos provenientes do TCU, foi possível identificar que as auditorias têm como medida de intensidade da accountability o pressuposto do controle burocrático destacado por Denhardt e Denhardt (2000), uma vez que a base para a investigação está enlaçada à Lei $\mathrm{n}^{\circ}$ 9.790/99, que qualifica as Oscips e institui e disciplina os Termos de Parceria. Além de tal pressuposto, há ênfase em investigar a administração das organizações envolvidas a fim de resguardar os recursos financeiros direcionados a projetos de interesse social 
(Kluvers, 2003; Koppell, 2005), bem como verificar a execução dos dispêndios financeiros do Termo de Parceria.

As limitações deste estudo importam em não ter diretamente como verificar a prestação de contas das Oscips, por não haver obrigatoriedade de apresentação. Entende-se que a prestação de contas é uma formalização do dever dos responsáveis por recursos públicos em apresentar onde estes foram aplicados. Verificar tais recursos demanda ter fontes confiáveis de informação de forma oportuna e tempestiva. Também, destaque ao fato de que a análise está limitada as Oscips constantes nos 77 acórdãos analisados.

Para futuras pesquisas, além da responsividade, esperam-se análises aprofundadas sobre o desempenho dessas organizações e, em caso de irregularidades comprovadas, as punições às organizações e aos responsáveis por fiscalizar os termos de parceria em sua execução. Também sugere-se que a amostra seja expandida a fim de observar outras entidades sem fins lucrativos.

\section{REFERÊNCIAS}

Abouassi, K., \& Trent, D. L. (2016) NGO Accountability from an NGO Perspective: Perceptions, Strategies, and Practices. Public Administration and Development, 36(4), 283296.

Arvidson, M. (2009). Impact and evaluation in the UK third sector: reviewing literature and exploring ideas. Third Sector Research Centre, 27, 1-28.

Benjamin, L. M. (2008). Account space: How accountability requirements shape nonprofit practice. Nonprofit and Voluntary Sector Quarterly, 37(2), 201-223.

Bode, I., \& Brandsen, T. (2014). State-third sector partnerships: A short overview of key issues in the debate, introduction to the special issue on state-third sector partnerships. Public Management Review, 16, 1055-1066.

Bovens, M. (2007). Analysing and assessing accountability: A conceptual framework 1. European law journal, 13(4), 447-468.

Ministério da Administração Federal e Reforma do Estado. (1997). Organizações sociais. Cadernos MARE da Reforma do Estado. Brasília, DF.

Lei $n^{\circ}$ 9.637, de 15 de maio de 1998. (1998). Dispõe sobre a qualificação de entidades como organizações sociais, a criação do Programa Nacional de Publicização, a extinção dos órgãos e entidades que menciona e a absorção de suas atividades por organizações sociais, e dá outras providências. Brasília, DF. Recuperado em 31 janeiro, 2018, de http://www.planalto.gov.br/CCivil_03/leis/L9637.htm

Lei $n^{\circ}$ 9.790, de 23 de março de 1999. (1999). Dispõe sobre a qualificação de pessoas jurídicas de direito privado, sem fins lucrativos, como Organizações da Sociedade Civil de Interesse Público, institui e disciplina o Termo de Parceria, e dá outras providências. Brasília, DF. $\begin{array}{lllll}\text { Recuperado em } & 31 & \text { janeiro, } & \text { de }\end{array}$ http://www.planalto.gov.br/CCIVIL_03/leis/L9790.htm

Tribunal de Contas da União. (2000). Manual de auditoria de natureza operacional. Brasília, DF. 
Cameron, W. (2004). Public accountability: Effectiveness, equity, ethics. Australian Journal of Public Administration, 63(4), 59-67.

Campos, G. M. A., Moreira, R. de L., \& Scalzer, R. S. (2015). Financial reporting: reflection on transparency in the third sector. Sociedade, contabilidade e gestão, 9(3), 130-142.

Castaldelli Júnior, E. (2010). Divulgação de desempenho de órgãos públicos: uma Análise de Conteúdo dos relatórios de gestão do Tribunal de Contas da União. Tese de Doutorado, Universidade de São Paulo, São Paulo, SP, Brasil.

Chisolm, L. B. (1995). Accountability of nonprofit organizations and those who control them: The legal framework. Nonprofit Management and Leadership, 6(2), 141-156.

Clifford, D., Geyne-Rahme, F., \& Mohan, J. (2013). Variations between organisations and localities in government funding of third-sector activity: evidence from the national survey of third-sector organisations in England. Urban Studies, 50(5), 959-976.

Coule, T. M. (2015). Nonprofit governance and accountability: Broadening the theoretical perspective. Nonprofit and Voluntary Sector Quarterly, 44(1), 75-97.

Dart, R. (2004). The legitimacy of social enterprise. Nonprofit management and leadership, 14(4), 411-424.

Denhardt, R. B., \& Denhardt, J. V. (2000). The new public service: Serving rather than steering. Public administration review, 60(6), 549-559.

Di Pietro, M. S. Z. (2005). Direito administrativo (18a ed.). São Paulo: Editora Atlas.

Do Carmo Dalto, C., Nossa, V., \& Lopo Martinez, A. (2014). Recursos de Convênio entre Fundações de Apoio e Universidades Federais no Brasil: um estudo dos acórdãos do Tribunal de Contas da União (TCU). Revista Universo Contábil, 10(2), 6-23.

Ebrahim, A. (2003a). Accountability in practice: Mechanisms for NGOs. World development, 31(5), 813-829.

Ebrahim, A. (2003b). Making sense of accountability: Conceptual perspectives for northern and southern nonprofits. Nonprofit Management and Leadership, 14(2), 191-212.

Ebrahim, A. (2009). Placing the normative logics of accountability in "thick" perspective. American Behavioral Scientist, 52(6), 885-904.

Fry, R. E. (1995). Accountability in organizational life: problem or opportunity for nonprofits?. Nonprofit Management and Leadership, 6(2), 181-195.

Gray, R., Bebbington, J., \& Collison, D. (2006). NGOs, civil society and accountability: making the people accountable to capital. Accounting, Auditing \& Accountability Journal, 19(3), 319-348.

Guimarães, L. S. R. (2008). Governança no terceiro setor: estudo descritivo-exploratório do comportamento de conselhos curadores de fundações empresariais no Brasil. Tese de Doutorado, Universidade de São Paulo, São Paulo, SP, Brasil. 
Furneaux, C., \& Ryan, N. (2014). Modelling NPO-Government Relations: Australian case studies. Public Management Review, 16(8), 1113-1140.

Garrow, E. E. (2010). Receipt of government revenue among nonprofit human service organizations. Journal of Public Administration Research and Theory, 21(3), 445-471.

Godoy, A. (1995). Pesquisa qualitativa: tipos fundamentais. RAE-Revista de Administração de Empresas, 5(3): 20-29.

Graciliano, E. A., Moreira Filho, J. C., Nunes, A. D. P., Pontes, F. C. D. M., \& Zampa, F. F. (2010). Accountability na administração pública federal: contribuição das auditorias operacionais do TCU. Pensar Contábil, 12(47).

Grateron, I. R. G. (1999). Auditoria de gestão: utilização de indicadores de gestão no setor público. Caderno de estudos, 21,01-18.

Kendall, J. \& Knapp, M. (2000) Measuring the performance of voluntary organizations. Public Management Review, 2(1), 105-132.

Kluvers, R. (2003). Accountability for performance in local government. Australian Journal of Public Administration, 62(1), 57-69.

Koppell, J. G. S. (2005), Pathologies of accountability: ICANN and the challenge of "multiple accountabilities disorder". Public administration review, 65(1), 94-108.

Knutsen, W. L, \& Brower, R. S. (2010). Managing expressive and instrumental accountabilities in nonprofit and voluntary organizations: A qualitative investigation. Nonprofit and Voluntary Sector Quarterly, 39(4), 588-610.

Landim, L. (1987). Non-governmental organizations in Latin America. World Development, 15, 29-38.

Lawry, R. P. (1995). Accountability and nonprofit organizations: An ethical perspective. Nonprofit Management and Leadership, 6(2), 171-180.

Mânica, F. B. (2007). Panorama históricolegislativo do Terceiro Setor no Brasil: do conceito de Terceiro Setor à Lei das OSCIP. Terceiro Setor. Empresas e Estado-Novas Fronteiras entre o Público e o Privado. Minas Gerais: Fórum, 163-194.

Martins, H. F. (2004). Reforma do Estado na era FHC: diversidade ou fragmentação da agenda de políticas de gestão pública. Rio de Janeiro: EBAPE/FGV.

Miller, J. L. (2002). The board as a monitor of organizational activity: The applicability of agency theory to nonprofit boards. Nonprofit Management and Leadership, 12(4), 429450.

Nakagawa, M. (1993). Introdução à controladoria: conceitos, sistemas, implementação. São Paulo: Atlas. 
Paes, J. E. S. (2004). Fundações e entidades de interesse social: aspectos jurídicos, administrativos, contábeis e tributários. Brasília Jurídica.

Ranci, C. (2015). The Long-Term Evolution of the Government-Third Sector Partnership in Italy: Old Wine in a New Bottle?. Voluntas: International Journal of Voluntary and Nonprofit Organizations, 26(6), 2311-2329.

Rocha, A. C. (2009). Accountability na Administração Pública: a Atuação dos Tribunais de Contas. Anais do Encontro Nacional da ANPAD, São Paulo, SP, Brasil, 33.

Rodríguez, M. Del M. G.; Pérez, M. Del C. C., \& Godoy, M. L. (2012) Determining factors in online transparency of NGOs: A Spanish case study. Voluntas: International Journal of Voluntary and Nonprofit Organizations, 23(3), 661-683.

Salamon, L. M., \& Anheier, H. K. (1996). Defining the nonprofit sector: the United States. Johns Hopkins University Institute for Policy Studies.

Sano, H. (2003). Nova Gestão Pública e accountability: o caso das organizações sociais paulistas. Tese de Doutorado, Fundação Getúlio Vargas, São Paulo, SP, Brasil.

Saxton, G. D., \& Guo, C. (2011). Accountability online: Understanding the web-based accountability practices of nonprofit organizations. Nonprofit and Voluntary Sector Quarterly, 40(2), 270-295.

Shaw, S., Allen, J. B. (2006). "We Actually Trust the Community:" Examining the dynamics of a nonprofit funding relationship in New Zealand. Voluntas: International Journal of Voluntary and Nonprofit Organizations, 17(3), 211-220.

Sinclair, A. (1995). The chameleon of accountability: forms and discourses. Accounting, organizations and Society, 20(2-3), 219-237.

Soldi, A. R., Hatz, C. R., Santos, G. R. dos, \& Silva, M. M. da. (2007). Transparência no terceiro setor: um estudo sobre as organizações filantrópicas. Jovens Pesquisadores, 4(1), 1-13.

Sunder, S. (2014). Teoria da Contabilidade e do Controle. São Paulo: Atlas.

Thompson, P., \& R. Williams. (2014). Taking Your Eyes Off the Objective: The Relationship Between Income Sources and Satisfaction with Achieving Objectives in the UK Third Sector. Voluntas: International Journal of Voluntary and Nonprofit Organizations, 25(1), 109-137.

Valencia, L. A. R., Queiruga, D., \& González-Benito, J. (2015). Relationship between transparency and efficiency in the allocation of funds in nongovernmental development organizations. Voluntas: International Journal of Voluntary and Nonprofit Organizations, 26(6), 2517-2535.

Wainwright, S. (2002). Measuring impact: A guide to resources. London, NCVO. 